\title{
Nodes, Guardians and Signs: Raising Barriers to Human Trafficking in the Tourism Industry
}

\author{
Alexandros Paraskevas (PhD) \\ Professor in Strategic Risk Management \\ London Geller College of Hospitality and Tourism \\ University of West London \\ St. Mary's Road, Ealing, London, W5 5RF \\ United Kingdom \\ E-mail: Alexandros.Paraskevas@uwl.ac.uk \\ (Corresponding Author) \\ Maureen Brookes (PhD) \\ Reader in Marketing \\ Oxford School of Hospitality Management \\ Oxford Brookes University \\ Headington Campus, Oxford, Ox3 oBP \\ United Kingdom \\ E-mail: meabrookes@brookes.ac.uk
}

\begin{abstract}
:
Trafficking in human beings (THB) is a growing criminal activity involving the movement of victims by force or coercion for sexual or labour exploitation. THB is often facilitated unwittingly by tourism businesses. This study sought ways to disrupt the opportunities for THB in the hotel sector through the application of criminology theories. A qualitative study was conducted in three European countries (UK, Finland and Romania), employing semi-structured key stakeholder interviews, a survey of hotel managers and focus groups. Using concepts primarily from crime pattern theory, hotels were confirmed as THB activity spaces and 'crime journeys' were mapped with the nodes where offenders and their victims converge with different 'guardians' (hotel employees and managers). Warning signs and critical intervention points where THB opportunities can be disrupted were also identified. The resulting framework of the trafficked victim's journey can be used by any tourism business wishing to help prevent this crime.
\end{abstract}

Key Words: criminal opportunity, critical intervention points, crime pattern theory, hotels, human trafficking, modern slavery, warning signs

\section{Acknowledgements}

This article reports on the findings of a project that has been funded with support from the European Commission (HOME/2013/ISEC/AG/THB/4000005873). It reflects the views only of the authors, and the European Commission cannot be held responsible for any use which may be made of the information contained therein. The authors would like to thank the following people for their contributions in this project: Prof Angela Roper, Prof Simonetta Manfredi, Dr Madalina Mocan, Dr Pekka Iivari, Dr Sonia Morano- Foadi, Kate Clayton-Hathway, Niko Niemisalo, Aulikki.Laitinen-Tolonen, Mihai Cazacu and Andreaa Salvan. 


\section{Highlights:}

- Trafficking in human beings (THB) as a criminal activity in the tourism sector.

- Criminology theories and symbolic interactionism offer a THB prevention framework.

- Trafficked victims' journeys in a hotel are mapped.

- Signs, guardians and critical intervention points identified to disrupt THB.

- Potential barriers that can disrupt THB crimes in a hotel are proposed.

\section{Introduction}

Trafficking in human beings (THB) is a form of modern day slavery affecting almost every country in the world (Europol, 2016). It involves the movement of victims through force, psychological coercion or abuse, predominantly for the purposes of sexual or labour exploitation. THB is a rapidly growing criminal activity despite concerted efforts worldwide to address it. Hopper and Hidalgo (2006) maintain that the victims' physical and psychological erosion through chronic fear become the "invisible chains" (p. 185) that bind them into slavery. While there is great disparity between the number of estimated victims, e.g., 21 million by the ILO (2017) and 45.8 million by the Walk Free Foundation (2017), there is consensus that official statistics reflect only the "tip of the iceberg" (Di Nicola, 2007:53). The Palermo Protocol, the UN Protocol to Prevent, Suppress and Punish Trafficking in Persons (2000), is the most globally adopted legislative framework (UNODC, 2016), requiring signatories to make THB a criminal offence (Hernandez and Rudolph, 2015).

Researchers acknowledge that THB often involves the use of legitimate businesses, which, knowingly or unknowingly, are enablers of THB (Aronowitz et al., 2010; Skrivankova, 2010), providing opportunities for the crime to take place. Tourism businesses, by their very nature, facilitate the movement and accommodation of traffickers and their victims and thus are potential THB enablers. There are numerous examples of airlines, travel agencies and restaurants being used by traffickers for their crimes (Bulman, 2017; Carolin, et al., 2015; Deutsch, 2016; Donovan, 2010). A growing recognition of THB within the tourism industry has led to many commendable initiatives such as the introduction of the Code of Conduct for the Protection of Children from Sexual Exploitation in Travel and Tourism. However, the majority of these efforts to date have focussed on increasing the awareness of THB and particularly of child sexual exploitation (CSE). There is arguably a need to increase awareness of other types of sexual and labour trafficking and to identify measures to disrupt the business of THB within the tourism industry.

Tourism researchers have thus far considered human trafficking within broader studies of sex tourism (Cansel et al., 2009; Chang and Chen, 2013, Uzama, 2011) and labour exploitation, mainly of migrant workers (Hjalager, 2008; Joppe, 2012; Robinson, 2013). Child exploitation has been of particular attention (Brackenridge et al., 2014; Magablih and Naamneh, 2010) with researchers suggesting prevention practices in the travel and tourism (Richter, 2005; Tepelus, 2008) and hotel sectors (Kalargyrou and Woods 2015). Researchers have also highlighted the potential for mega events to provide opportunities for sex trafficking (Brackenridge et al., 2014; Matheson and Finkel, 2013). However, there is currently no research that offers a more in-depth study of THB as a crime in the tourism sector and that proposes a methodology for identifying critical intervention points where a tourism destination or tourism businesses can raise barriers to disrupt this crime. 
This paper contributes to this gap by combining theories of criminology and social science to understand THB patterns and the behaviour of traffickers and victims within tourism industry and identify ways to disrupt this criminal business. It reports the findings of a hotel study partly funded by the European Commission's Directorate of Home Affairs under the Internal Security Fund's targeted call for Trafficking in Human Beings. The hotel industry, was deemed an appropriate research context given its susceptibility to both sexual and labour trafficking (Annison, 2013; Tuppen, 2013). In doing so, it answers calls for further research on the prevention of THB (Birkenhager, 2014; Kabance, 2014) and the involvement of the private sector in its prevention (Friesendorf, 2007; Rogoz, 2016).

The research makes two distinct contributions to our understanding of THB. Firstly, it identifies critical intervention points within hotels where trafficking for sexual and labour exploitation can be disrupted. Secondly, it identifies potential warning signs at each of these intervention points that can alert staff members to potential THB incidents and practical measures that can be implemented to erect barriers to effectively disrupt THB. Whilst the framework is hotel-specific, the overall approach of mapping a trafficked victims journey, of identifying critical intervention points, and of recognising warning signals, may be applied by any tourism business or destination management organisation.

The paper begins by defining THB and examines it as a business opportunity to identify the reasons for its prevalence. Criminological theories and concepts are then used to examine the opportunities for THB generally and then within the hotel sector. The research design is presented next, before the findings of the study are discussed. A hotel-specific framework which depicts the trafficked victims' journey is then developed. The conclusion identifies the implications and limitations of the study and directions for future research.

\section{Trafficking in Human Beings (THB)}

Although there are different definitions of THB adopted globally (Wylie and McRedmond, 2010), the Palermo Protocol (2000) applies the following definition.

The recruitment, transportation, transfer, harbouring or receipt of persons, by means of the threat or use of force or other forms of coercion, of abduction, of fraud, of deception, of the abuse of power or of a position of vulnerability or of the giving or receiving of payments or benefits to achieve the consent of a person having control over another person, for the purpose of exploitation. Exploitation shall include, at a minimum, the exploitation of the prostitution of others or other forms of sexual exploitation, forced labour or services, slavery or practices similar to slavery, servitude or the removal of organs or other types of exploitation. (Article 3, para. (a))

This definition identifies the three major elements of THB: (a) the act (what is done); (b) the means (how it is done); and (c) the purpose (why it is done) as depicted in Table 1. Victims of THB include both adults and children; male and female. While Table 1 identifies different purposes or types of exploitation, the majority (79\%) of victims are trafficked for sexual exploitation and 18\% for labour exploitation (UNODC, 2016). This definition and the elements of THB clearly highlight why it is a human rights crime. The following section however, examines THB as a business opportunity, albeit a criminal one. 


\begin{tabular}{|l|l|l|}
\hline \multicolumn{1}{|c|}{ Act of THB } & \multicolumn{1}{|c|}{ Means of THB } & \multicolumn{1}{c|}{ Purpose of THB } \\
\hline Recruitment & Threat or use of force & Sexual exploitation \\
Transport & Abduction & Prostitution of others \\
Transfer & Coercion & Forced labour or services \\
Harbouring & Deception & Modern slavery \\
Receipt of persons & Fraud & Servitude \\
& Abuse of power & Removal of organs \\
& Vulnerability & Other types of exploitation \\
& Payments or benefits to person in & (e.g. forced criminality, \\
& control of another person & begging, marriage) \\
& & \\
\hline
\end{tabular}

Table 1: The Three Major Elements of Trafficking in Human Beings (THB) Adapted from United Nations (2000) The protocol to prevent, suppress and punish trafficking in persons especially women and children, supplementing the United Nations convention against transnational organized crime. GA res, 55, p.25 (November 15).

\subsection{THB as a Business Opportunity}

There are numerous factors that underpin the growth of THB, with some scholars (e.g., Simmons and Lloyd, 2010) arguing that THB represents the dark side of globalisation. These factors can be divided into those that 'push' victims and those that 'pull' victims into THB (Wheaton et al., 2010). Victims might be 'pushed' into falling prey to traffickers due to poverty and unemployment, limited social support (Bales, 2005), poor or limited education (Kelly, 2002), an unstable family life, domestic violence, war or civil unrest (Hughes, 2000) and underlying cultural attitudes and practices (Ejalu, 2006). Accordingly, Aronowitz et al. (2010) advise that victims share the common trait of being vulnerable or being in a vulnerable situation within their countries of origin. Victims are also 'pulled' into trafficking by environmental factors in destination countries where there are job or educational opportunities, higher wages, political stability and the demand for sexual services and foreign labour (Kabance, 2014). These pull factors increase the willingness of victims to migrate, making them more susceptible to traffickers (Hernandez and Rudolph, 2015).

Together, 'push' and 'pull' factors provide traffickers with a business opportunity by creating an economic market for THB; the physical or virtual places that connect demand from buyers with the supply from sellers either directly or through intermediaries (Wheaton et al., 2010). THB is reported to be particularly profitable (Hernandez and Rudolph, 2015). Those trafficked for sexual exploitation can generate between 100 and $1000 \%$ profits and those trafficked into forced labour provide over 50\% return on investment (Pennington et al., 1999). The forced prostitution of a single woman amounts to US $\$ 100,000$ profits a year (Aronowitz et al., 2010). The relatively cheap cost of a trafficked individual in today's marketplace combined with few barriers to market entry or exit (Wheaton et al., 2010) further explain the growth in the business of THB. Combined supply, demand and profitability explain why THB is an attractive business opportunity. The importance of opportunity is also recognised by researchers who examined THB from a criminal perspective as the following section explains.

\subsection{THB as a Criminal Opportunity}

Three theories within the field of criminology, combined to develop the domain of environmental criminology, highlight the importance of opportunity: rational choice, routine activity and crime pattern theories. A fundamental concept of criminal law is that a crime needs 
a motive, means, and an opportunity (Cornish and Clarke, 1987). Motives are the reasons for choosing an illegal activity over a legal one and they are typically monetary or economic (McKendall et al., 2002). Rational choice theorists focus on this economic perspective to explain the motive for criminal activity. Criminals are considered to make rational choices based on their consideration of costs and benefits when they observe an opportunity (Lutya and Lanier, 2012). Included in the decision-making process is an estimation of the risks involved. Criminologists recognise the importance of perceptions and that criminals make decisions under conditions of bounded rationality (Birks et al., 2012; Sato, 2013). However, as the preceding section demonstrates, the benefits of THB outweigh the costs and Kara (2011) maintains that "the risks involved are almost non-existent" (p. 69). As such, strong motives exist for undertaking THB provided criminals have the means or the instruments available to carry out a task. For THB, means include the supply of victims, identified above, the manpower for their recruitment, transportation and exploitation, as well as the communication and distribution channels to market their services (Kara, 2009).

Routine activity theorists recognise motivated offenders as one of the three key elements of a crime. They argue that opportunities for crime arise when motivated offenders, a suitable target and the absence of a capable 'guardian' converge in space and time (Gialopsos and Carter, 2015). Hollis et al. (2013) explain capable guardianship as a human element with the ability to deter crime through their presence, proximity and capability. In other words, guardians must exist, be close by and be able to take action against the criminal. In the absence of a capable guardian or if the guardian is ineffective or negligent, crimes are more likely to occur (Cohen and Felson, 1979; Hollis et al., 2013). These guardians can be located within a social or physical environment, either of which can facilitate an opportunity (Hollis et al., 2013). In a physical environment, such as a building, place managers serve as guardians and have the potential to control and regulate behaviour (Eck and Weisburd, 1995).

Building on these two theoretical perspectives, crime pattern theory asserts that offenders learn about their environment during legitimate everyday activities and that crime takes place where and when their awareness space intersects with criminal opportunities. The routine activities of the motivated offender form mobility patterns which evolve into awareness and activity spaces (Brantingham and Brantingham, 2008). Awareness spaces include all the places an offender has familiarity with, whereas activity spaces are those an offender has contact with as part of their routine activity (Bernasco, 2010). Activity spaces are made up of (a) nodes that are the places routinely visited by criminals and (b) the pathways travelled between them (Iwanski et al., 2011). Nodes may offer conditions conducive to specific crimes and thus create opportunity (Pooley and Ferguson, 2017; Rossmo, 2014). The offenders' movement from node to node therefore becomes a 'crime journey' (Bernasco, 2014).

Using the concept of nodes and pathways, crime pattern theory focuses on where and when the convergence of offenders, victims and the absence (or inactivity) of guardians occurs and helps to explain the distribution of crime across places (Eck and Weisburd, 1995). Researchers have examined where this convergence occurs at the macro (e.g. regions, communities, neighbourhoods) and micro level (e.g., specific buildings or types of business) (Groff et al., 2014). At both levels, these places can be distinguished as to whether they are crime attractors or crime generators (Pooley and Ferguson, 2017). The main distinction between the two is whether offenders purposefully visit the place to commit the crime or act on impulse while there. Nonetheless the characteristics of either type of place are important. For example, the permeability of a region or the accessibility of a building are important considerations when creating interventions or barriers to prevent crime (Groff et al., 2014). So too, is the degree to which guardians can recognise and control deviant behaviour within a premise. According to symbolic interaction theorists (Blumer, 1969; Mead, 1934), recognising deviance depends on 
guardians' 'definition of the situation', whereby subjective meaning is imposed on objects, events and behaviours. This meaning is continuously shaped through socialisation and influenced by prior experiences, education, knowledge of norms, customs and beliefs as well as by individual and collective needs and wants (Carter and Fuller, 2016).

Taken together, rational choice, routine activity, crime pattern theory and symbolic interactionism can be used to develop a conceptual framework for THB crime prevention (Fig. 1), increasing our understanding of the decision making that occurs when evaluating opportunities, where and how opportunities are created and where and how interventions can be made to aid in crime prevention. The following section considers the opportunity for the crime of THB in the hotel sector.

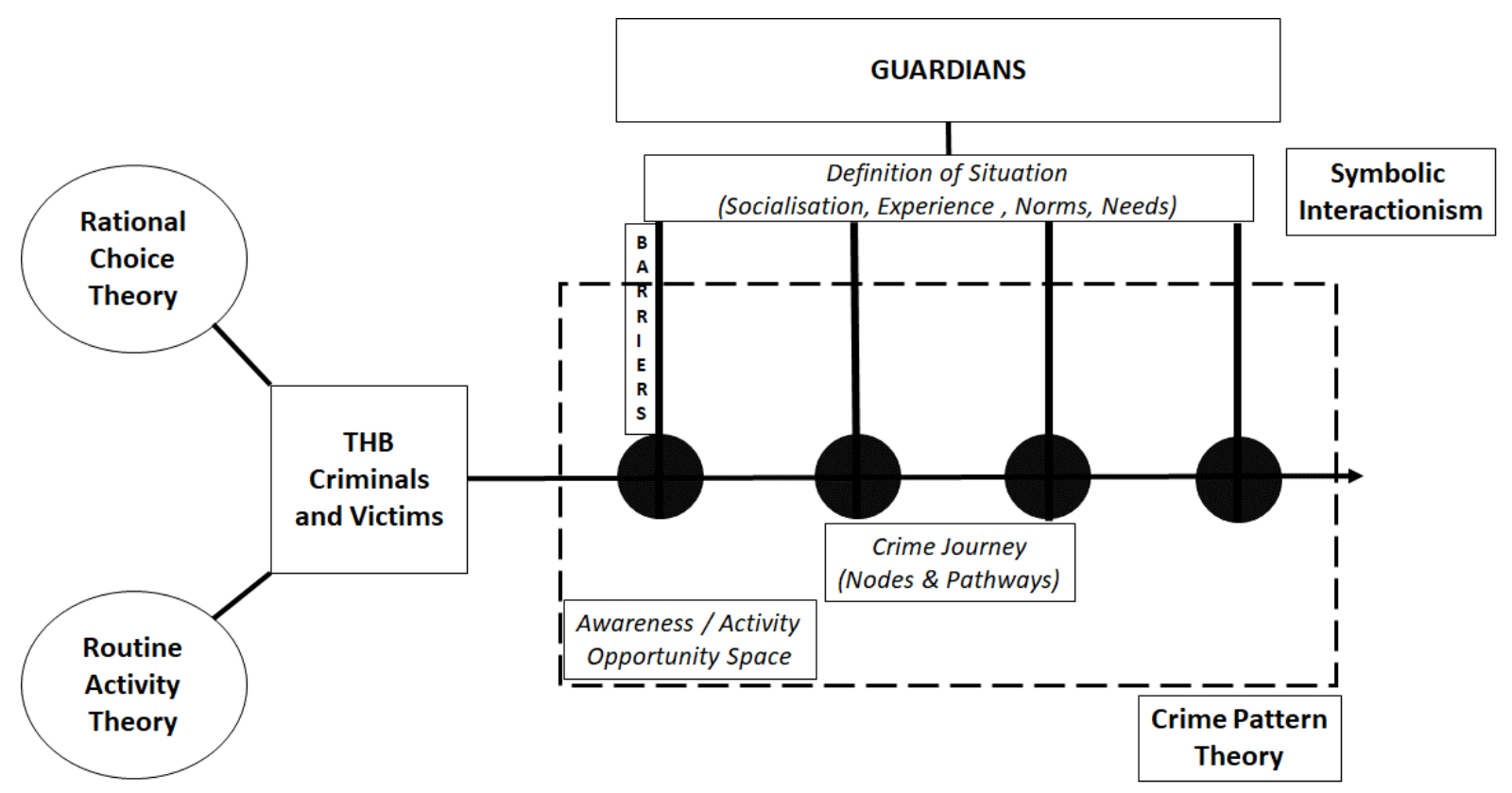

Fig. 1 - A Conceptual Framework for THB Crime Prevention

\subsection{THB in the Hotel Sector}

Drawing on crime pattern theory, the tourism industry can be considered as an activity space that provides opportunities at the micro level for the crime of THB to occur. Lutya and Lanier (2012) argue that tourism businesses facilitate both the harbouring and transfer of trafficked victims. Hotels, in particular, are increasingly used as vehicles for the sexual exploitation of trafficked victims (Annison, 2013) and the US National Human Trafficking Hotline identifies that hotels are a more likely venue for sexual trafficking than commercial brothels (NHTH, 2016). The use of forced labour is also growing in hotels (EUROSTAT, 2015; Tuppen, 2013). Hotels, therefore, can and do provide both the means and the opportunity for traffickers to do business. As enablers of THB (Skrivankova, 2010), they also have a potential role to play in its prevention.

Given the multi-faceted nature of the hotel business, and the opportunity for both sexual and labour exploitation, hotels may contain different nodes, where the traffickers, as offenders, converge with the target or THB victim. As such, there are different employees who could act in the role of guardians. When used for the purpose of sexual exploitation, guardians could be any employee with a customer-facing role, whereas guardians of labour exploitation, are more likely to be those with responsibility for recruitment and procurement as well as department 
heads. The presence, proximity and capability of guardians to regulate behaviour (Hollis et al., 2013 ) in both types of THB would be variable. Similarly, according to the symbolic interaction theory, their recognition and interpretation of the possible warning signs emanated by traffickers and victims would depend on the level of interaction with these individuals (socialisation process) and their understanding of this crime (experience and training). Possible disruption of the THB journey within the hotel would depend on the anti-THB standards and policies (norms) the hotel has in place and the guardians' personal and professional characteristics.

Understanding the nodes and paths, the role of the guardians and the types of signs they would consider as a warning for THB is therefore arguably important to identify where and how opportunities for THB can be disrupted within the hotel sector. These disruptions would reduce the opportunities for traffickers to do business as they would increase risks and costs and thereby reduce the profitability of THB (Aronowitz et al., 2010). This study therefore sought to:

i) assess the awareness of THB in the hotel sector and identify critical intervention points where the opportunity for THB could be disrupted;

ii) identify the warning signs of THB at different critical intervention points to develop the capability of hotel guardians and

iii) identify barriers that can be erected to disrupt the business of THB.

\section{Research Design}

As part of a wider European Commission funded project, the study was conducted within the three European countries where the project partners were located; the UK, Romania and Finland. Given the exploratory nature of the study and the sensitivity of the topic, a qualitative research approach was adopted (Altinay et al., 2016) consisting of three stages.

\subsection{Stage 1}

In the first stage, semi-structured interviews were conducted with key informant stakeholders in all three countries. Participants were recruited via combined purposive and snowball sampling techniques. Informants were selected based on their experience in their sector, their understanding of THB as a crime and their professional standing nationally and internationally as depicted in Table 2. The interviewees were asked to give examples and details of THB cases they were aware of, explain the warning signs that were or could have been spotted and what actions could be taken to prevent future THB incidents. The interview schedule was developed in English, then translated and back translated into each partner's language to ensure translational equivalence (Usinier, 2011). In total, 29 semi-structured interviews each lasting up to one hour were conducted by trained interviewers in the partners' local language.

\begin{tabular}{|c|c|c|c|c|}
\hline Stakeholder Sector and Code & $\begin{array}{c}\text { United } \\
\text { Kingdom }\end{array}$ & Romania & Finland & Total \\
\hline Hotel Corporate Executives (HI) & 3 & 2 & 3 & 8 \\
\hline Tourism Industry Corporate Executives (TI) & 1 & 1 & 1 & 3 \\
\hline Law Enforcement (LE) & 1 & 1 & 2 & 4 \\
\hline Security Services (SS) & 3 & 1 & 1 & 5 \\
\hline
\end{tabular}




\begin{tabular}{|c|c|c|c|c|}
\hline NGO / Charity (NC) & 1 & 3 & 2 & 6 \\
\hline Sector Stakeholder (ST) & 1 & 1 & 1 & 3 \\
\hline Total & $\mathbf{1 0}$ & $\mathbf{9}$ & $\mathbf{1 0}$ & $\mathbf{2 9}$ \\
\hline
\end{tabular}

Table 2: Sample of Interviewees by Country and Sector

\subsection{Stage 2}

The second stage of the research sought to build on stage 1 through a qualitative survey of hotel managers in the three countries. Specifically, the surveys sought to explore whether the respondents felt that THB is an issue for hotels; the types of THB hotels are vulnerable to; the warning signs by which traffickers and victims may be identified; and the possible barriers that may disrupt their 'journey' through a hotel. As before, the survey was developed in English and then translated and back translated into the partner's language to ensure translational equivalence (Usunier, 2011). A convenience sample was employed as the researchers needed to utilise personal contacts within hotel chains and professional associations who recognised both the sensitivity and importance of the study. 147 usable surveys were returned, 94 from the UK, 29 from Finland and 24 from Romania, reflecting to a reasonable extent the respective size of the hotel markets in these countries. Although both independent and chain hotels were included in the targeted sample, the majority of respondents were employed within luxury and mid-scale, chain-affiliated hotels with more than 100 rooms. 48 of the respondents were hotel general managers $(\mathrm{GM})$ while the rest were heads of departments (HoD).

\subsection{Stage 3}

The third and final stage of the research included 3 focus groups in the UK which aimed to: (a) get deeper insight on potential warning signs from traffickers and victims and possible barriers to erect within hotels by presenting and discussing distinct cases of THB identified in the study; and (b) enrich and validate the THB journeys developed in Stage 2. Participants were members of Hotel Watch, a UK public-private partnership designed to identify and minimise crime within the accommodation industry, including the crime of THB. These partnerships are collaborations between police, independent and chain-affiliated hotels and other accommodation businesses and the local government council. The participants were presented with THB cases and asked to individually identify nodes, pathways, guardians, warning signs and barriers. They then were presented with the two THB journeys (in the hotel's front- and back-of-house) derived from the data analysis for comment. The discussion with these different stakeholders helped to revise and enrich these THB journeys.

\subsection{Data analysis}

The digital recordings of the interviews in stage 1 were transcribed, anonymised, memberchecked and then analysed by the partners in their respective languages. Interviewees were coded according to their professional role (e.g., interviewees representing an anti-THB NGO would be coded as NC1, NC2 .. NC6, sector stakeholders ST1, ST2 ... ST3. The same process was followed for the stage 2 surveys (SR1, etc.). It is important to note that the survey data was not analysed quantitatively and nor was it intended to be. Its purpose was to gather as much data as possible on THB in the hotel sector in line with the study's objectives: to identify all potential critical intervention points, warning signs and potential barriers to disrupt the opportunity for THB. This analytical approach facilitated the development of the framework of the victim's journey. 
The analysis of the data in the first two stages drew on the framework analysis approach developed for applied policy research by Ritchie and Spencer (1994). This approach involves five interconnected stages of: familiarisation through review and reading; identification of a thematic framework; indexing; charting; mapping and interpretation (Ritchie et al., 2013). The thematic framework in this study was shaped from the familiarisation stage when the focus on data coding was placed at the nodes and pathways of traffickers and victims in a hotel, the guardians, the warning signs of trafficking and the barriers that could be erected. Following the indexing stage, the researchers used textual codes to link specific quotes to these topics and identify further codes to inter-relate them (i.e., nodes with guardians, nodes with signs, guardians with barriers, etc.). Inter-rater reliability was ensured with the involvement of a third party (a member of the project's advisory board). The mapping process allowed the visual display of the relevant data. The results were translated into English by professional translators and shared with the rest of the partners for data consolidation (Usinier, 2011). This consolidation enabled the development of a framework that depicts a trafficked victim's journey in hotels (front- and back-of-house), identifying critical intervention points where signs of THB may be detected and barriers erected to disrupt THB. The third stage of the study helped to further enrich and refine the model of the victim's journey and to validate warning signs and barriers.

\section{Findings and Discussion}

The findings are presented according to study's three objectives. All interviewees, survey respondents and focus group members are referred to as project participants.

\subsection{Objective One: To assess the awareness of THB in the hotel sector and identify critical intervention points where the opportunity for THB could be disrupted}

\subsubsection{THB as a Concern for the Hotel Sector}

Wheaton et al. (2010: 123) refer to the different types of THB as the "differentiated products" traffickers offer. This study revealed that many of these differentiated products are offered within the hotel sector. Participants acknowledged their awareness of cases of forced prostitution, domestic servitude, forced labour both in hotels and in their supply chains (including the construction of hotels) and forced criminality. Forced criminality is a specific type of forced labour where trafficked victims are coerced to commit an activity that is contrary to the law, such as "pick-pocketing, shop-lifting, drug trafficking and other similar activities which are subject to penalties and imply financial gain" (Antislavery, 2014, p. 89). The study identified cases where trafficked victims were placed as employees in hotels in order commit fraud. Child sexual exploitation (CSE), was also acknowledged as a form of forced prostitution in hotels, despite the many industry initiatives to eradicate this specific type of THB. Surprisingly, many participants felt that CSE was not an issue in the industry. One possible explanation is the belief that this type of THB has been sufficiently addressed by the various industry-targeted initiatives. However, more seasoned law enforcement participants (SS2, SS3, SS5) argued that the main issue is that it is often quite challenging to identify a minor both from a legal and a physical perspective. Additionally, some focus groups participants indicated that many hotel employees do not perceive age difference of guestroom occupants as an issue of particular concern. 
Participants from all three countries in stages 1 and 2, felt that sexual exploitation through forced prostitution was the type of THB that the industry was most vulnerable to. However, the study also identifies confusion between 'voluntary' prostitution and 'forced' prostitution. According to one indicative participant:

"Most prostitution is not trafficking. These girls and boys do it because they like the glamour of hotels, the luxury lifestyle and the clothes and shoes that the money they make can help them afford. They do it for a few years and then they 'retire' or they open their own escort services." (SR34)

While this finding is consistent with previous research (Lutya and Lanier, 2012; Outshoorn, 2005 ) the survey also revealed that many industry members are not particularly concerned with this type of THB. As such, the study identifies that this confusion between voluntary and forced prostitution may enhance the opportunity for THB within the hotel sector, particularly in countries where prostitution is an accepted practice within the hotel sector and is not a criminal offence.

The findings also revealed cases of forced labour within the industry. However, many participants were surprised to hear that this could be the case. As one commented,

"Honestly, the thought never crossed my mind that a staff member or agency people would be victims of trafficking. I always believed that agency staff are cheap labour just because they are economic immigrants. But victims, never!" (SR38)

One hotel security consultant with international experience in hotel chains, summed up the situation hotels face accordingly,

"Criminals always seek paths of least resistance in order to make money. Unfortunately, due to a misconstrued understanding of hospitality and discreetness and a strange mix of naivety and complicity, our industry offers plenty of these paths in spite of the efforts of security and operations." (SS2)

Hotels are therefore crime attractors (Pooley and Ferguson, 2017), purposefully visited by traffickers in order to commit the crime of THB. Looking at the different types of THB conducted in hotels (mainly sexual and labour exploitation), traffickers are arguably using hotels as activity spaces (Iwanski et al., 2011) in both the front and the back-of-house.

\subsubsection{Crime Journeys, Nodes, Guardians and Critical Intervention Points}

Following the processes dictated by crime pattern theory (Brantingham and Brantingham, 2008), the analysis of the data from Stages 1 and 2 enabled the mapping of the crime journeys of traffickers and their victims in a hotel (Fig. 2) with specific nodes and pathways (Iwanski et al., 2011). 
Activity Space: Hotel Front-of-House
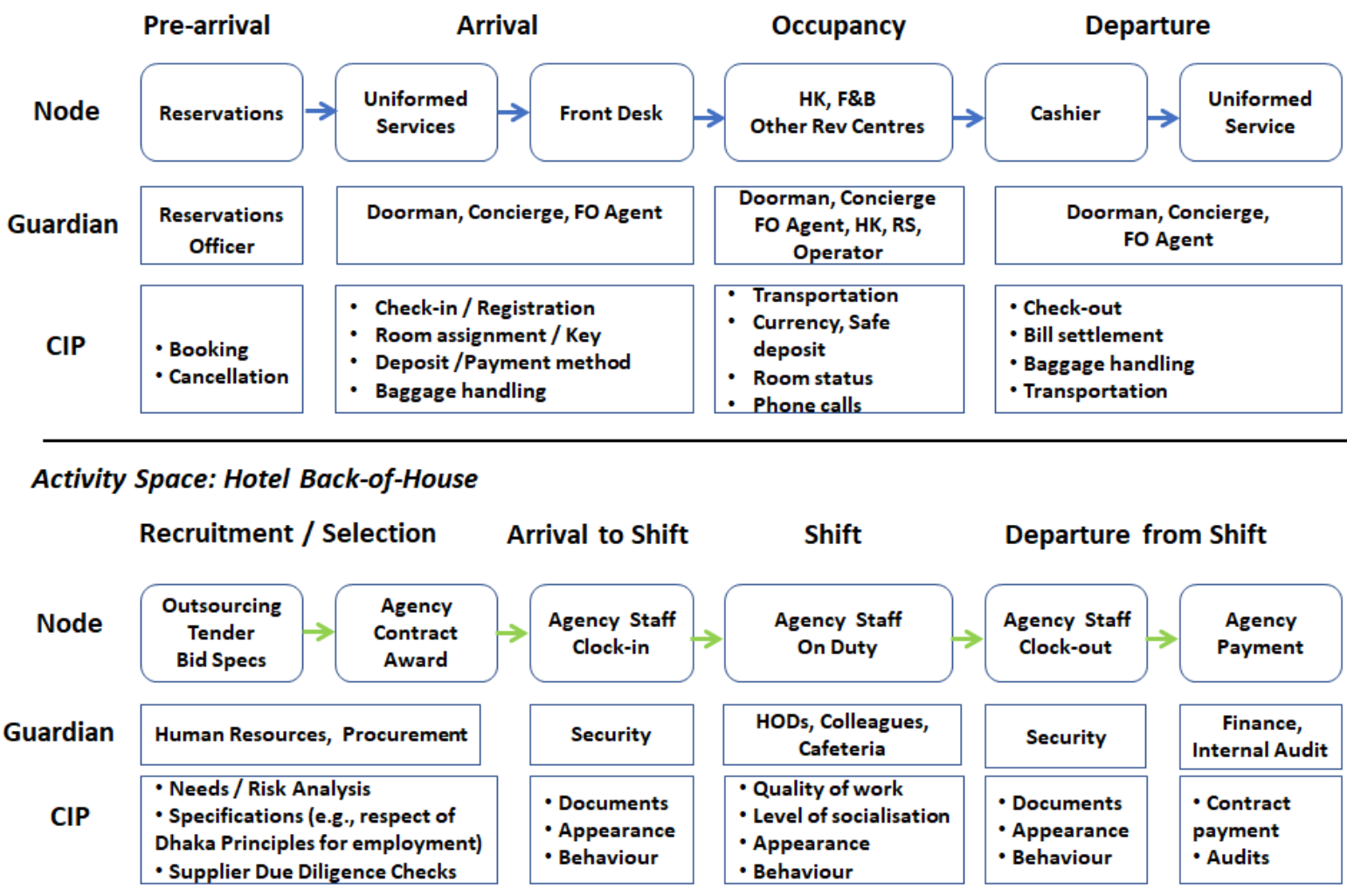

Fig. 2 - A Framework of the Trafficking Victim's Journey in a Hotel

Each node is a contact point between the trafficker and/or victim which involves one or more potential guardians within a hotel. Although the absence of a guardian at a node may be attractive to traffickers, in most cases, it is their inability or unwillingness to act that provides better opportunities for THB (Gialopsos and Carter, 2015). The activities related to sexual exploitation normally require access to guestrooms and, therefore, are front-of-house activities taking place at the pre-arrival, arrival, occupancy and departure stages of the guest cycle. For example, at the 'reservation node' the study identified traffickers' advanced bookings for airport hotel rooms for two or three nights. After travel visas were obtained the reservations were subsequently cancelled. The inability of the automated reservations system to detect such cancellation patterns offered traffickers an exploitable opportunity. The activities associated with labour exploitation would normally be linked to recruitment, outsourcing and purchasing as back-of-house functions. The growing use of outsourcing of housekeeping, maintenance and gardening functions were practices identified that exposed hotels to labour trafficking. The lack of appropriate vetting at the 'tendering node' or the 'agency contract award node' provides traffickers with the opportunity to use their victims for these contracts.

The survey data, in particular, indicated that the lack of anti-THB standards and procedures, or their poor enforcement by guardians, create enhanced opportunities for traffickers (Cohen and Felson, 1979; Hollis et al., 2013). Poor enforcement was predominantly attributed to a lack of awareness and training and most participants stated that they had not received any formal THB training. The study also revealed that guardians often lack authority and are therefore inhibited from taking action in response to suspected THB incidents. One participant reported that, " $m y$ general manager does not allow me to ask questions about the identity of people checking-in" 
[SR22]. Attitude or the willingness to act was also an influential factor for some guardians. As one suggested, "I'm not paid to do the job of the UK Border Agency" [SR70]. Cases were also reported (HI4, TI2, SS3) where guardians facing the dilemma between moral decisionmaking and achieving financial targets, opted for the latter. Furthermore, the study also identified that some employees' contracts were terminated when they did opt for the moral decision.

In addition to presenting opportunities for criminals, the nodes also represent points at which critical interventions can occur by 'capable guardians' (Cohen and Felson, 1979; Hollis et al., 2013) in order to disrupt THB crimes. Fig. 2 presents the critical intervention points (CIP) in each node identified by the study. For these interventions to take place, however, guardians must be able to recognise the warning signs of THB, as discussed in the following section.

\subsection{Objective Two: To identify the warning signs of THB at different critical intervention points to develop the capability of hotel guardians}

The data from all three stages of the study revealed a number of warning signs that may alert hotel staff to potential incidents of THB. Through analysis, these signs were categorised according to their source; either the trafficker, the victim or the interaction between them and the guardians. They were also categorised according to the node where they can be observed and the meaning that can be attributed to them. Through the thematic analysis, the signs identified were also categorised as to whether they were particularly related to sexual or labour trafficking and then mapped onto the nodes identified where critical interventions could occur to disrupt the crime of THB.

The potential warning signs generally fell within two broad categories related to physical appearance of victims or to the behaviours of traffickers and/or victims. Participants from the three stages placed more emphasis on one category of signs, dependent on their background. For example, those with law enforcement and hotel security backgrounds reported signs that had more to do with the physical appearance of victims; whereas participants from antitrafficking NGOs reported more signs that had to do with the behaviour of victims. Experienced hotel operators reported more behavioural signs of traffickers and victims as hotel guests.

\subsubsection{Physical Appearance Front or Back-of-House}

The study revealed a number of physical appearance indicators could be taken into consideration in suspected THB incidents. For victims, under- or over-dressing for the premises and signs of malnourishment, exhaustion and/or physical abuse are potential warning signs. The disparity in age and race of people checking-in (e.g. between traffickers and potential victims) are also potential signs. However, as noted above, focus group participants suggested that hotel employees are not concerned about age differences. In addition, they also reported that to question any race differences between guests would be politically incorrect.

\subsubsection{Behaviour as Guests at the Front-of-House}

Participants identified a number of guest behaviours that serve as potential warning signs at different stages of the guest cycle. These signs are considered not that common, although not necessarily outside the norms of guest behaviour. Examples include requests for isolated rooms 
or rooms near fire exits when making reservations or on arrival and limited or no luggage, advance payment for the entire stay in cash or lack of formal identification on arrival. During occupancy, prolonged use of do-not-disturb signs; excessive numbers of visitors to the room; unusual housekeeping requests and exceptional levels of noise in the room are potential signs as are guests occupying the same room leaving at different times or guests collected by the same taxi driver at departure.

Some signs identified related to the interaction between traffickers and victims. For example, the complete dependence of victims on traffickers, where victims display fearful, anxious, or submissive behaviour and the sense that they are "at loss for words even in the most routine conversation" with hotel staff (NC4) are warning signs. SS3 and SS5 attributed this emotional dependence not only to the psychological or physical abuse by traffickers but also to a trauma bond (like the 'Stockholm syndrome') through which victims feel compelled to protect the person inflicting the trauma.

\subsubsection{Behaviour of Victims at the Back-of-House}

Most of the participants reporting back-of-house signs agreed that victims show clear signs of isolation. They do not socialise with other colleagues, take limited breaks and, when in the staff cafeteria, they sit alone and do not engage with other staff. They usually don't possess a mobile phone and refuse offers of a ride home from colleagues. Victims are often dropped off and collected, usually by the same vehicle, at a distance from the employee entrance and out of sight of closed-circuit television cameras.

Participants, especially in Stage 3, emphasised that these potential signs of THB should not be interpreted in isolation, but within the wider context of the suspected traffickers' and victims' behaviours. They agreed that 'capable guardians' must first be able to recognise signs of deviant behaviour from the general 'noise' and impose correct meaning on objects, events and behaviours observed (Carter and Fuller, 2016) in order to be able to intervene at a node and disrupt THB crimes (Groff et al., 2014).

These findings support the importance of training in order to develop 'capable guardians' in the hotel. The survey revealed, however, that the participants who had undertaken some form of THB training had mixed views as to its effectiveness. The front office manager of an upscale hotel in Romania reported:

"Any training is useful as it expands our knowledge on the topic; however, for us to be effective we need a strong commitment from the 'top' with proper policies and standards; signing the Code and taking a seminar will never be enough." (SR126)

Similarly, a housekeeping HoD in a UK midscale hotel said that she was "thrilled with the training" but her general manager would not take action on any of her reports and she could "not risk" reporting directly to the police (SR45). A GM of another midscale hotel reported that "the 'one-size-fits-all' anti-THB training approach that our company implements at all levels of the organisation is inappropriate." She argued that a more nuanced delivery of 
training should be given to senior and executive-level management with a focus on the development of an "anti-trafficking culture that will fully support a change of policies and standards to combat this crime; mere awareness training alone is not enough to change the perceptions within the company" (SR67). This response is consistent with the symbolic interaction theory principles which suggest that, apart from knowledge and experience, the shaping of 'meaning' requires also appropriate organisational norms and values as well as an alignment of individual and collective needs (Carter and Fuller, 2016). It is only through such actions that effective barriers to disrupt THB can be erected as discussed in the following section.

\subsection{Objective Three: To identify barriers that can be erected to disrupt the business of THB.}

The study identified numerous potential procedures (interventions) to deter THB at the different activity spaces and disrupt the trafficked victim's journey at critical intervention points.

At the front-of-house activity space, these barriers were categorised into customer identification, documented payment procedures and guest and/or visitor monitoring. One participant advised,

"We should ideally be present with the guest throughout their hotel experience, from reservation to checkout; vigilance is required by everyone on the hotel and signs should be picked up and reported." (SR89)

This comment is reflective of Bales' (2007) argument that, 'effective deterrence of human trafficking means targeting every stage of human trafficking involvement' (p. 31). Similarly, at the back-of-house activity space, barriers were identified as due diligence action for agencies; audit processes for agencies and suppliers; documentation, observation of and engagement with agency and suppliers' staff. The signs and barriers identified were then mapped against the critical intervention points and guardians (Fig. 2). Examples of this mapping process are presented in Tables 3 and 4.

This mapping process was a critical step in the development of the final framework which drew on crime pattern theory and the conceptual framework presented in Figure 1. The Trafficked Victim's Journey in a Hotel identifies the critical intervention points (activity spaces with nodes) and the pathways between them for both sexual and labour trafficking, taking place respectively in the front or back-of-house. At each intervention point, potential guardians who converge with traffickers and their victims according to routine pattern theory (Gialopsos and Carter, 2015) are also included. The framework also identifies where the 'means' (Kara, 2009) and the 'favourable' opportunities (McKendall et al., 2002) may occur within hotels. As such, it enables hotels to identify which potential barriers should be erected to disrupt these opportunities for THB so that traffickers find it more difficult to use the industry for their criminal business. As such, it also disrupts the nexus between motive, means and opportunity to combat THB. 


\begin{tabular}{|c|c|c|c|}
\hline $\begin{array}{l}\text { Critical } \\
\text { Intervention } \\
\text { Point }\end{array}$ & Guardian & Potential Signs & Potential Barriers to Disrupt THB \\
\hline $\begin{array}{l}\text { Pre-Arrival: } \\
\text { Reservations }\end{array}$ & Reservation Agents & $\begin{array}{l}\text { - Unusual block bookings by } 3^{\text {rd }} \text { party providers } \\
\text { - Requests for rooms near fire exits } \\
\text { - Queries about hotel rooms access/security policies }\end{array}$ & $\begin{array}{l}\text { - Monitor cancellation rates and source of reservations } \\
\text { - Probe for reasons for request } \\
\text { - Provide clear details on hotel policy and enquire as to whether } \\
\text { guest is expecting visitors }\end{array}$ \\
\hline Arrival & $\begin{array}{l}\text { Uniformed Services: } \\
\text { Door staff } \\
\text { Bell staff } \\
\text { Valet staff }\end{array}$ & $\begin{array}{l}\text { - Different guests arriving with same taxi driver } \\
\text { - Limited luggage on arrival } \\
\text { - Service refusal, parking in isolated area }\end{array}$ & $\begin{array}{l}\text { - Take details of licence and keep note of dates } \\
\text { - Politely enquire whether luggage is arriving later } \\
\text { - Require and verify car registration details }\end{array}$ \\
\hline $\begin{array}{l}\text { Arrival: } \\
\text { Check-In }\end{array}$ & $\begin{array}{l}\text { Front Desk Agents } \\
\text { Concierge }\end{array}$ & $\begin{array}{l}\text { - Only one person completes registration process } \\
\text { - Guests display signs of abuse or exhaustion } \\
\text { - Inappropriate clothing for type of property } \\
\text { - Guest identification does not match name on } \\
\text { reservation } \\
\text { - Multiple keys requested }\end{array}$ & $\begin{array}{l}\text { - Insist all guests register and provide photo identification } \\
\text { - Enquire politely if everything is okay and assign room that can } \\
\text { be monitored throughout stay } \\
\text { - Require passport or other formal photo identification } \\
\text { - Issue keys only to those named on registration }\end{array}$ \\
\hline $\begin{array}{l}\text { In-Room } \\
\text { Occupancy }\end{array}$ & $\begin{array}{l}\text { Housekeeping Staff } \\
\text { Room Service Staff } \\
\text { Security } \\
\text { Operator/Guest } \\
\text { Services }\end{array}$ & $\begin{array}{l}\text { - Multiple visitors to guest rooms } \\
\text { - Excessive use of Do Not Disturb signs } \\
\text { - Excessive housekeeping requests for towels and/or } \\
\text { linens } \\
\text { - Evidence of drug, condom, and camera use } \\
\text { - Room service orders for alcohol where minors are } \\
\text { - } \text { staying, staff denied room entry } \\
\text { - Numerous external phone calls to room } \\
\end{array}$ & $\begin{array}{l}\text { - Keep record of visitors, engage in conversation and make note } \\
\text { if they are not able to identify guest by name } \\
\text { - Implement policy to service room once every } 24 \text { hours } \\
\text { - Keep record of requests, particularly if DND sign also used. } \\
\text { Check number of guests registered } \\
\text { - Inform security staff for investigation } \\
\text { - Implement policy that room checked every } 24 \text { hours } \\
\text { - Keep diary entries }\end{array}$ \\
\hline $\begin{array}{l}\text { Departure: } \\
\text { Check-Out }\end{array}$ & Front Desk Agents & - Credit card does not match that used for booking & $\begin{array}{l}\text { Ensure new credit card validated before departure and scan } \\
\text { copy of photo identification of guest }\end{array}$ \\
\hline $\begin{array}{l}\text { Departure: } \\
\text { Check-Out }\end{array}$ & $\begin{array}{l}\text { Uniformed Services: } \\
\text { Door staff } \\
\text { Bell staff } \\
\text { Valet staff }\end{array}$ & $\begin{array}{l}\text { - Guests collected by same taxi driver as on arrival } \\
\text { - Guests collected some distance from hotel }\end{array}$ & $\begin{array}{l}\text { - Make note of licence and keep note of dates } \\
\text { - Take details of vehicle and licence }\end{array}$ \\
\hline
\end{tabular}

Table 3: Examples of Signs and Barriers to Disrupt Sex Trafficking 


\begin{tabular}{|c|c|c|c|}
\hline $\begin{array}{c}\text { Critical } \\
\text { Intervention } \\
\text { Point } \\
\end{array}$ & Guardian & Potential Signs & Potential Barriers to Disrupt \\
\hline $\begin{array}{l}\text { Outsourcing } \\
\text { Tender } \\
\text { Bid } \\
\text { Specification }\end{array}$ & Procurement & $\begin{array}{l}\text { - Supplier charging significantly lower costs. } \\
\text { - Unknown or unclear provenance of goods. }\end{array}$ & $\begin{array}{l}\text { - Due diligence checks on supplier with tax payment } \\
\text { evidence including references. } \\
\text { - As above with supplier signing business ethics code of } \\
\text { conduct. }\end{array}$ \\
\hline $\begin{array}{l}\text { Agency Staff } \\
\text { Clock-In }\end{array}$ & Security & $\begin{array}{l}\text { - Staff have no identification documentation. } \\
\text { - Staff never arrive independently at work. }\end{array}$ & $\begin{array}{l}\text { - Staff identification on arrival as security measure. } \\
\text { - Engage staff member in casual conversation about } \\
\text { journey. }\end{array}$ \\
\hline $\begin{array}{l}\text { Agency Staff } \\
\text { Clock-Out }\end{array}$ & Security & $\begin{array}{l}\text { - Staff always depart alone. } \\
\text { - Staff never accept ride home from colleagues } \\
\text { - Staff always collected by the same vehicle. }\end{array}$ & $\begin{array}{l}\text { - Engage staff in casual conversation about journey home } \\
\text { and where they live. } \\
\text { - Take details of vehicle and licence }\end{array}$ \\
\hline $\begin{array}{l}\text { Agency } \\
\text { Payment }\end{array}$ & $\begin{array}{l}\text { Finance } \\
\text { Internal Audit }\end{array}$ & - Any of the above signs reported & $\begin{array}{l}\text { - Undertake audit of agency or supplier to evaluate } \\
\text { potential risks of THB }\end{array}$ \\
\hline
\end{tabular}

Table 4: Examples of Signs and Barriers to Disrupt Labour Trafficking 


\section{Conclusion and Implications}

The study sought to address a current gap in the tourism literature by combining theories of criminology and social science to develop a mapping approach of a trafficked victim's journey through a tourism business. This approach facilitates the identification of critical intervention points where 'capable guardians' (members of the tourism business) can disrupt this journey. This disruption can be achieved by the development of 'node-specific' policies and standards that will be implemented every time THB warning signs are detected by guardians. As such, the study contributes to the tourism literature by providing a comprehensive framework for businesses to use to combat the crime of THB in all its forms.

While the victim's journey presented in this study may be hotel-specific, the overall detection and prevention framework can be applied to other sectors of the tourism industry (e.g., airlines, travel agencies, etc.) or to tourism destinations by adapting the activity spaces, pathways, nodes, guardians and critical intervention points accordingly. The study confirms extant research that tourism activities and tourism businesses are crime attractors for both sexual and labour exploitation of THB victims. It also reveals that different types of THB can potentially take place both within the business and its supply chain. However, despite the growth in THB globally, awareness of this criminal activity within tourism businesses is limited predominantly due to a lack of training. The study also reveals that even when training occurs, the lack of authority or of effective reporting procedures undermine efforts to disrupt THB. As such, tourism businesses may remain vulnerable to exposure to THB and provide opportunities for traffickers. Nonetheless, the study also identifies how to limit this exposure through the identification of the activity spaces, pathways and nodes within the business where critical interventions might occur. It also identifies the potential THB warning signs for each intervention point, the guardians who might intervene and the barriers that could be erected to disrupt THB.

The findings have both practical and research implications for tourism businesses and destination management organisations. At the business level, the study reveals that there is more work to be done to create awareness of THB within the tourism sector and to improve the training of employees as guardians to recognise the potential warning signs. It also suggests a need for tourism businesses to develop a stronger anti-THB culture to ensure that guardians have the authority to act on their suspicions, and that they will be supported by senior managers when they do so. As such, the study points to the need to develop and implement clear THB reporting systems with the involvement of senior management. Further research to identify THB victims' journey in other sectors is thus warranted to address these needs in order to more effectively disrupt THB.

Further research is also required at the tourism destination level to identify activity spaces and trafficking journeys, pathways and nodes, as well as the appropriate stakeholders who will act as 'guardians'. The development of intervention strategies and policies that will disrupt all forms of THB and will help the rehabilitation of trafficking 'survivors' are two other areas that need attention by both tourism policy makers and scholars. Bales (2007) argues that the two major tools for fighting THB are awareness and resources. The mapping approach of the 
trafficked victim's journey in this study is designed as a practical resource that tourism authorities and businesses can use to increase awareness, support THB training and to identify where barriers may be erected to disrupt THB opportunities.

\section{References}

Altinay, L., Paraskevas, A. and Jang, S.S., (2016). Planning Research in Hospitality and Tourism. London: Routledge.

Annison, R. (2013), "Hidden in plain sight: Three years on: updated analysis of UK measures to protect trafficked persons", The Anti Trafficking Monitoring Group, available at:

http://www.antislavery.org/includes/documents/cm_docs/2013/h/hidden_in_plain_sight.pdf (accessed 28 January 2015).

Antislavery (2014), "Trafficking for forced criminal activities and begging in Europe: exploratory study and good practice examples" available at: http://www.antislavery.org/wpcontent/uploads/2017/01/trafficking_for_forced_criminal_activities_and_begging_in_euro pe.pdf (accessed 12 May 2016).

Aronowitz, A., Theuermann, G. and Tyurykanova, E. (2010), "Analysing the business model of trafficking in human beings to better prevent the crime", available at: http://www.osce.org/files/documents/c/f/69028.pdf (accessed 9 January 2015).

Bales, K. (2005), Understanding Global Slavery, University of California Press, Berkley, California.

Bales, K. (2007), Ending Slavery: How We Free Today's Slaves, University of California Press, Berkley, California.

Bernasco, W. (2010), "A sentimental journey to crime effects of residential history on crime location choice”, Criminology, Vol. 48 No. 2, pp. 389-416.

Bernasco, W., (2014). “Crime journeys: Patterns of offender mobility”, in Tonry, M. (ed.) Oxford Handbooks Online in Criminology and Criminal Justice. Oxford University Press, Oxford, available at:

http://www.oxfordhandbooks.com/view/10.1093/oxfordhb/9780199935383.001.0001/oxfor dhb-9780199935383-e-49?rskey=dpazVA\&result=1 (accessed 4 May 2016)

Birkenhager, P. (2014), Trapped by Division, Master Thesis, Twente University.

Birks, D., Townsley, M. and Stewart, A. (2012). "Generative explanations of crime: using simulation to test criminological theory”, Criminology, Vol. 50 No. 1, pp. 221-254. 
Blumer, H. (1969), Symbolic interactionism: perspective and method, University of California Press, Berkeley.

Brackenridge, C. H., Rhind, D., and Palmer-Felgate, S. (2014). "Locating and mitigating risks to children associated with major sporting events". Journal of Policy Research in Tourism, Leisure and Events, Vol. 7, No. 3, pp.237-250.

Brantingham, P. and Brantingham, P. (2008), "Crime Pattern Theory" in Wortley, R. and Mazerolle, L. (eds.) Environmental Criminology and Crime Analysis, Routledge, Oxon, pp.78-93.

Bulman, M. (2017). "Flight attendant saves teenage girl from human trafficking after seeing secret note", The Independent, Monday 6 February, available at:

http://www.independent.co.uk/news/world/americas/flight-attendant-save-teenage-girlhuman-trafficking-secret-note-sheila-frederick-alaska-airlines-a7564506.html (accessed 8 March 2017).

Cansel, A., Ekiz, E. H., and Bavik, A. (2009). "Sex tourism in Northern Cyprus: investigating the current situation. Tourism Analysis, Vol. 14, No. 5, pp. 677-689.

Carolin, L., Lindsay, A. and Victor, W., (2015). "Sex Trafficking in the Tourism Industry". Journal of Tourism and Hospitality, Vol. 4, No. 4, 166-171.

Carter, M.J. and Fuller, C., (2016), "Symbols, meaning, and action: The past, present, and future of symbolic interactionism", Current Sociology, Vol. 64, No. 6, pp.931-961.

Chang, C. F., and Chen, M. H. (2013). "Dependency, Globalization and overseas sexrelated consumption by East Asians", International Journal of Tourism Research, Vol. 15, No. 6, pp. 521-534.

Cohen, L.E. and Felson, M., (1979). "Social change and crime rate trends: A routine activity approach”, American Sociological Review, Vol. 44, No.4, pp.588-608.

Cornish, D. and Clarke, R. (1987), "Understanding crime displacement: An application of rational choice theory”, Criminology, Vol. 25 No. 4, pp. 933-947.

Deutsch, A. (2016). "Police find travel agency for traffickers, drug hauls in European raids", Reuters, Wednesday 19 October, available at: http://www.reuters.com/article/useuropol-crime-idUSKCN12J0M6?il=0 (accessed 27 November 2016).

Di Nicola, A. (2007) 'Researching into human trafficking: issues and problems' in M. Lee (ed.) Human Trafficking, Devon: Willan Publishing, pp. 49-72.

Donovan, J. (2010). “American Airlines Flight Attendant: I See Human Trafficking on the Plane", NBC Washington, NITESIDE, Wednesday 12 May, available at: 
http://www.nbcwashington.com/blogs/niteside/VID_Airline_Stewardess_All_National_. html (accessed 18 June 2016).

Eck, J. E. and Weisburd, D. (1995), "Crime places in crime theory". In Eck, J. E. and Weisburd, D. (eds), Crime and place, crime prevention studies (Vol. 4), Willow Tree Press, Monsey, New York, pp. 1-33.

Ejalu, W. (2006), "From home to hell: the telling story of an African woman's journey and stay in Europe", in Beeks, K and Amir, D (eds.) Trafficking and the Global Sex Industry, Lexington Books, New York, pp. 165-186.

Europol (2016), Situation report: Trafficking in human beings in the EU, available at: https://ec.europa.eu/antitrafficking/sites/antitrafficking/files/situational_report_trafficking_in_human_beings_europol.pdf (accessed 12 March 2017).

Eurostat (2015), Trafficking in human beings, available at: https://ec.europa.eu/antitrafficking/sites/antitrafficking/files/eurostat_report_on_trafficking_in_human_beings_2015 edition.pdf (accessed 23 March 2017).

Freisendorf, C. (2007), "Pathologies of security governance: Efforts against human trafficking in Europe", Security Dialogue, Vol. 38 No. 3, pp. 379-409.

Gialopsos, B. and Carter, J. (2015), “Offender Searches and Crime Events”, Journal of Contemporary Criminal Justice, Vol. 31 No. 1, pp. 53-70.

Groff, E., Elesh, D., McGovern, D and Johnson, L. (2014), "Permeability across a metropolitan area: conceptualizing and operationalizing a macrolevel crime pattern theory", Environment and Planning, Vol. 46, No. 1, pp. 129-152.

Hernandez, D. and Rudolph, A. (2015), "Modern Day Slavery: What drives human trafficking in Europe?”, European Journal of Political Economy, Vol. 38, pp.118-139.

Hjalager, A. M. (2008). "The illegal economy in the restaurant sector in Denmark". Tourism and Hospitality Research, Vol. 8, No. 3, pp. 239-251.

Hollis, M., Felson, M. and Welsh, B. (2013), "The capable guardian in routine activities theory: A theoretical and conceptual appraisal”, Crime Prevention and Community Safety, Vol. 15 No. 1, pp.65-79.

Hopper, E. and Hidalgo, J., (2006). "Invisible Chains: Psychological Coercion of Human Trafficking Victims”, Intercultural Human Rights Law Review, Vol. 1, No. 1, pp. 185-209.

Hughes, D. (2000), “The 'Natasha' trade: the transnational shadow market of trafficking in women”, Journal of International Affairs, Vol. 53 No 2, pp. 1-18. 
International Labour Office (ILO). (2017), Forced labour, modern slavery and human trafficking available at http://www.ilo.org/global/topics/forced-labour/lang--ja/index.htm available (accessed 21 April, 2017).

Iwanski, N., Frank, R., Dabbaghiam, V., Reid, A. and Brantingham, P. (2011), “Analyzing an Offender's Journey to Crime: A Criminal Movement Model (CriMM)", European Intelligence and Security Informatica Conference DOI:10.1109/EISIC.2011.13

Joppe, M. (2012). "Migrant workers: challenges and opportunities in addressing tourism labour shortages”. Tourism Management, Vol. 33, No. 3, pp. 662-671.

Kabance, K. (2014), “The Globalization of Sex Trafficking”, International Affairs: Directed Research Project available at: https://ucollege.wustl.edu/files/ucollege/imce/iap.kabance.drp_.pdf (accessed 15 December, 2016).

Kalargyrou, V. and Woods, R. (2015). "An exploratory study of child commercial sexual exploitation in the hospitality industry in the United States". Hospitality \& Society, Vol. 5, No. 1, pp. 43-69.

Kara, S. (2009), Sex Trafficking: Inside the Business of Modern Slavery, Columbia University PressNew York.

Kara, S. (2011), "Supply and Demand Human Trafficking in the Global Economy", Harvard International Review, Vol. 33 No. 2, pp. 66-71.

Kelly, E. (2002), Journeys of Jeopardy: A Review of Research on Trafficking in Women and Children in Europe, International Organization for Migration (IOM), Geneva.

Lutya, T. and Lanier, M. (2012), “An Integrated Theoretical Framework to Describe Human Trafficking of Young Women and Girls for Involuntary Prostitution", in Maddock, J. (ed) Public Health, Social and Behavioural Health, In-Tech Open Access, Croatia, pp.555-570.

Magablih, K., and Naamneh, M. (2010). "Child labor in the tourism industry in Jordan". Tourism Analysis, Vol. 15, No. 1, pp. 89-97.

Matheson, C. M., and Finkel, R. (2013). "Sex trafficking and the Vancouver Winter Olympic Games: Perceptions and preventative measures", Tourism Management, Vol. 36, No. 4, pp. 613-628.

McKendall, M., Demar, B. and Jones-Rikkers, C. (2002), "Ethical compliance programs and corporate illegality: Testing the assumptions of the corporate sentencing guidelines", Journal of Business Ethics, Vol. 4 No 1, pp. 367-383. 
Mead, G.H. (1934), Mind, self, and society from the standpoint of a social behaviorist. University of Chicago Press, Chicago.

NHTH (2016), Hotline statistics by state, National Human Trafficking Hotline available at: https://humantraffickinghotline.org/states (accessed 30 March 2017).

Outshoorn, J., (2005), "The political debates on prostitution and trafficking of women". Social Politics: International Studies in Gender, State and Society, Vol. 12, No.1, pp.141155.

Pennington, J., Ball, A., Hampton, R., and Soulakova, J. (2009), “The Cross-National Market in Human Beings”, Journal of Macromarketing, Vol. 29 No. 2, pp. 119 - 134.

Polaris. (2014). Human trafficking cases reported per year, available at: (http://polarisproject.org/resources/2014-statistics (accessed 12 January 2016).

Pooley, K. and Ferguson, C. (2017), "Using environmental criminology theories to compare 'youth misuse of fire' across age groups in New South Wales", Australian and New Zealand Journal of Criminology', Vol. 50, No. 1, pp. 100-122.

Richter, L. K. (2005). "Not a minor problem: Developing international travel policy for the welfare of children”. Tourism Analysis, Vol. 10, No. 1, pp. 27-36.

Ritchie, J. and Spencer, L., (1994). "Qualitative data analysis for applied policy research", in Bryman, A. and Burgess, R. (Eds.), Analysing Qualitative Data. London: Routledge, pp. 173-194.

Ritchie, J., Lewis, J., Nicholls, C.M. and Ormston, R., (2013). Qualitative research practice: A guide for social science students and researchers. New York: Sage.

Robinson, R. N. (2013). "Darker still: present-day slavery in hospitality and tourism services". Hospitality \& Society, Vol. 3, No. (2), 93-110.

Rogoz, M. (2016), "Responses to Demand in the Context of Trafficking in Human Beings: Regulatory measures from twelve national contexts", DemandAT Working Paper No. 6, available at:

http://demandat.eu/sites/default/files/DemandAT_WP6_Rogoz_April2016_FINAL.pdf (accessed 16 January, 2017).

Rossmo, D.K., (2014), Geographic profiling. In Bruinsma G. and Weisburd, D. (eds) Encyclopedia of criminology and criminal justice, Springer, New York, pp. 1934-1942.

Sato, Y. (2013), “Rational Choice Theory”, Sociopedia.isa, DOI:10.1177/205684601372.

Simmons, S. and Lloyd, P. (2010), "Subjective Frames and Rational Choice: Transnational Crime and the Case of Human Trafficking", available at:

https://www.researchgate.net/profile/Beth_Simmons/publication/228151405_Subjective_F 
rames_and_Rational_Choice_Transnational_Crime_and the_Case_of_Human_Trafficking /links/0deec529c8581e2114000000.pdf (accessed 16 January, 2017).

Skrivankova, K. (2010), Between decent work and forced labour: examining the continuum of exploitation, Joseph Rowntree Foundation, York.

Tepelus, C. M. (2008). "Social responsibility and innovation on trafficking and child sex tourism: Morphing of practice into sustainable tourism policies?" Tourism and Hospitality Research, Vol. 8, No. 2, pp. 98-115.

Tuppen, H., (2013), “Addressing Human Trafficking in the Hospitality Industry”, Green Hotelier, 18 July, Know How Guides, International Tourism Partnership, available at: http://www.greenhotelier.org/know-how-guides/addressing-human-trafficking-in-thehospitality-industry/ (accessed 8 December 2016).

United Nations (2000) "Protocol to Prevent, Suppress and Punish Trafficking in Persons" available at:https://www.unodc.org/documents/treaties/UNTOC/Publications/TOC\%20Convention/T OCebook-e.pdf (accessed April 20, 2017).

UNODC (2016), Global report on trafficking in persons, United Nations Office on Drugs and Crime available at: https://www.unodc.org/documents/data-andanalysis/glotip/2016_Global_Report_on_Trafficking_in_Persons.pdf (accessed 30 March 2017).

Usunier, J. (2011). "Language as a Resource to Assess Cross-Cultural Equivalence in Quantitative Management Research". Journal of World Business, Vol. 46, No.3, pp.314319.

Uzama, A. (2011). "Sex tourism: a match through Japan's romance dori (street)". Tourism Analysis, Vol. 16, No. 6, pp. 677-692.

Walk Free Foundation (2017), Global Slavery Index available at: http://www.globalslaveryindex.org/ (accessed 01 April 2017).

Wheaton, E, Schauer, E. and Galli, T. (2010), "Economics of human trafficking", International Migration, Vol. 48 No. 4, pp. 114-141.

Wylie, G. and McRedmond, P. (2010), 'Human Trafficking in Europe", in Wylie, G. and McRedmond, P. (eds.), Human Trafficking in Europe, Character, Causes and Consequences, Palgrave MacMillon, Hampshire, UK. 